\title{
EXPERIMENTAL DETERMINATION OF LAMINAR BURNING VELOCITY OF BIOGAS AT PRESSURES UP TO 5 BAR
}

\author{
L. Pizzuti ${ }^{\mathrm{a}, \mathrm{b}}$, \\ C. A. Martins ${ }^{\mathrm{b}}$, \\ and L. R. Santos ${ }^{b}$ \\ ABSTRACT \\ This paper presents a very detailed description of a new cylindrical \\ constant volume combustion chamber designed for laminar burning \\ velocity determination of gaseous mixtures at ambient temperature \\ and initial pressure up to 6 bar. The experimental setup, the \\ ${ }^{a}$ Universidade Federal do ABC \\ Engenharia Aeroespacial \\ Santo André, São Paulo, Brasil \\ loreto.pizzuti@ufabc.edu.br \\ ${ }^{\mathrm{b}}$ Instituto Tecnológico de Aeronáutica \\ Laboratório de Combustão, Propulsão e \\ Energia - LCPE \\ Departamento de Propulsão \\ São José dos Campos, São Paulo, Brasil \\ cmartins@ita.br \\ leila@ita.br \\ Received: April 14, 2018 \\ Revised: May 28, 2018 \\ Accepted: August 18, 2018 \\ experimental procedure and the determination of the range of flame \\ radius for laminar burning determination are all described in details. \\ The laminar burning velocity of twelve synthetic biogas mixtures \\ has been studied. Initial pressure varying between 1 and 5 bar, \\ equivalence ratios, $\phi$, between 0.7 and 1.1 and percentage dilution, \\ with a mixture of $\mathrm{CO}_{2}$ and $\mathrm{N}_{2}$, between 35 and $55 \%$ have been \\ considered. Five experiments were run for each mixture providing a \\ maximum percentage standard deviation of $8.11 \%$. However, for \\ two third of the mixtures this value is lower than $3.55 \%$. A \\ comparison with simulation using PREMIX for both GRI-Mech 3.0 \\ and San Diego mechanisms has provided closer agreement for \\ mixtures with equivalence ratio closer to stoichiometry whereas for \\ $\phi=0.7$ the deviation is larger than $15 \%$ for all pressures. Mixtures \\ with lower equivalence ratio, higher dilution percentage and higher \\ initial pressure presents the lower values of laminar burning \\ velocity. \\ Keywords: laminar burning velocity; biogas; constant volume vessel; \\ outwardly propagating flames
}

\section{NOMENCLATURE}

A Area of flame surface $\left(\mathrm{m}^{2}\right)$

$d_{i} \quad$ Internal diameter $(\mathrm{m})$

$k \quad$ Stretch rate $\left(\mathrm{s}^{-1}\right)$

$\mathrm{Ka}$ Karlovitz number

$L \quad$ Markstein length (m)

$L_{b} \quad$ Markstein length of burned gases (m)

$L_{u} \quad$ Markstein length of unburned gases (m)

Ma Markstein number

$n \quad$ Number of moles

P Pressure (bar)

$S_{b} \quad$ Stretched burned flame propagation speed $(\mathrm{m} / \mathrm{s})$

$S_{b}{ }^{0} \quad$ Unstretched burned flame propagation speed $(\mathrm{m} / \mathrm{s})$

$S_{u} \quad$ Stretched laminar burning velocity $(\mathrm{m} / \mathrm{s})$

$S_{u}{ }^{0} \quad$ Unstretched laminar burning velocity $(\mathrm{m} / \mathrm{s})$

$u \quad$ Mixture velocity $(\mathrm{m} / \mathrm{s})$

$\mathrm{T}$ Temperature (K)

$\mathrm{T}_{\mathrm{a}} \quad$ Adiabatic flame temperature (K)

$t \quad$ Time (s)

$\mathrm{V} \quad$ Volume $\left(\mathrm{mm}^{3}\right)$

$x_{i} \quad$ Design factors

$\mathrm{X} \quad$ Volumetric fraction of species

Y Mass species concentration $\left(\mathrm{kg} / \mathrm{m}^{3}\right)$

\section{Greek symbols}

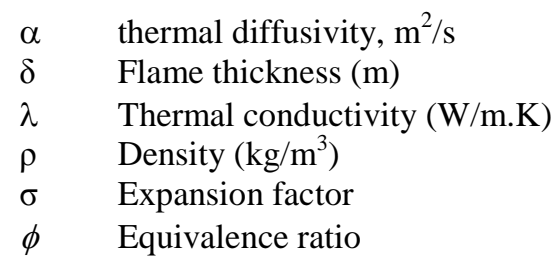

\section{Subscripts}

$\begin{array}{ll}\text { a } & \text { Adiabatic } \\ \text { b } & \text { Burned } \\ \text { F } & \text { Fuel } \\ \text { mix } & \text { Mixture } \\ \text { Ox } & \text { Oxidizer } \\ \text { st } & \text { Stoichiometric conditions } \\ \text { u } & \text { Unburned } \\ 0 & \text { Initial conditions }\end{array}$

\section{Superscripts}

$0 \quad$ Unstretched

\section{INTRODUCTION}

The continuous increasing world consumption of energy and the fast reduction of available cheap 
fossil fuels, joined with increasing attention to pollutant emissions has driven increasing interest in renewable sources of energy, including biofuels research and applications.

The availability of a great number of biofuels in the present context imposes a strict determination of the characteristics required for their application in internal combustion engines (ICEs). Biogas is particularly significant in this context because of its capability of application as fuels for internal combustion engines, which are the main power source for transport vehicles and commonly used for powering generators of electrical energy.

Biogas is the product of fermentation of man and animals biological activity waste products when bacteria degrade biological material in the absence of oxygen, in a process known as anaerobic digestion (Mihic, 2004). The composition of biogas may vary depending on the feedstock and the fermentation process. The main components are methane $\left(\mathrm{CH}_{4}\right)$ and carbon dioxide $\left(\mathrm{CO}_{2}\right)$ while minor constituents may be nitrogen $\left(\mathrm{N}_{2}\right)$, water vapor $\left(\mathrm{H}_{2} \mathrm{O}\right)$, hydrogen sulfide $\left(\mathrm{H}_{2} \mathrm{~S}\right)$, hydrogen $\left(\mathrm{H}_{2}\right)$, oxygen $\left(\mathrm{O}_{2}\right)$, carbon monoxide (CO) and ammonia $\left(\mathrm{NH}_{3}\right)$ (http://www.lemvigbiogas.com/BiogasHandbook.pdf, access date, 2012, November). However, for landfill biogas the percentage of $\mathrm{N}_{2}$ may reach up to $17 \%$ in volume (Rasi, 2009).

The laminar burning velocity, $S_{u}{ }^{0}$, is one of the most important parameters of a combustible mixture. It is a unique flame speed value, for a gas of a fixed composition, initial temperature and pressure, without further specification of hydrodynamic conditions, such as stretch rate, Reynolds number, etc. (Burke et al., 2007, Huzayyin et al., 2008). On a practical level, it affects the fuel-burning rate in ICEs and the engine's performance and emissions. On a fundamental level, the burning velocity is an important target for kinetic mechanism development and validation. Accurate determination of laminar burning velocity is extremely important for the development and validation of kinetic mechanisms for gasoline, diesel surrogate fuels and alternative fuels (Chen et al., 2009).

The experimental techniques employed in the measurement of laminar burning velocity can be broadly categorized into two general classes based on flame type: methods that are based on stationary flames and those that are based on propagating flames (Rallis and Garforth, 1980). Belong to the first group Bunsen flames, burner flat flames stabilized by heat flux method, counterflow or stagnation flames while tube flames and spherical expanding flames processed in closed vessels belong to the second group. The various hypotheses and difficulties involved in those configurations (low-cost solutions or hard engineering, stationary/non-stationary flames, planar/stretch free, stability, oscillations) explains the many experimental methods developed for velocity measurement. Detailed reviews of many of the different methodologies are given in the literature such as those by Andrews and Bradley (1972), Rallis and Garforth (1980) and Egolfopoulos and coworkers (2014).

There is in the literature a quite large amount of available measured and calculated laminar burning velocity data for the binary mixture of $\mathrm{CH}_{4}$ and $\mathrm{CO}_{2}$ at ambient conditions and some data at ICEs operating conditions. Zhu and coworkers (1989) determined the effect of $\mathrm{CO}_{2}$ on the laminar flame speeds of methane/ (Ar, $\mathrm{N}_{2}, \mathrm{CO}_{2}$ )-air mixtures over the stoichiometric range from very lean to very rich, i.e. $\phi$ from 0.4 to 1.8 , by using the counterflow method and numerical simulation by using a $\mathrm{C} 1$ mechanism and a full $\mathrm{C} 2$ mechanism. The effect of adiabatic flame temperature, $\mathrm{Ta}$, in the range from 1550 to $2250 \mathrm{~K}$ has been assessed by substituting $\mathrm{N}_{2}$ in the air by equal amounts of either $\mathrm{Ar}$ or $\mathrm{CO}_{2}$ such that the $\mathrm{O}_{2}$ concentration in the $\left(\mathrm{O}_{2}+\right.$ inert $)$ mixture is fixed at 21 volume percent. The effect of $\mathrm{CO}_{2}$ substitution is an adiabatic flame temperature decrease leading to a lower $\mathrm{S}_{u}{ }^{0}$ value. This behavior is explained as $\mathrm{CO}_{2}$ absorbs energy from the reaction due to its high specific heat and emits radiation to the surrounding due to its high emissivity.

Elia and coworkers (2001) experimentally determined the $\mathrm{S}_{u}{ }^{0}$ of mixtures of $\mathrm{CH}_{4}$ with up to $15 \%$ diluents $\left(\begin{array}{lllll}86 \% & \mathrm{~N}_{2} & \text { and } & 14 \% & \mathrm{CO}_{2}\end{array}\right)$ in air simulating those conditions found during idle in internal combustion engines employing the exhaust gas recirculation techniques to reduce the flame temperature, a major factor in the NOx creation. Laminar burning velocity is determined from pressure measurements in a constant volume combustion chamber in a range of pressures from 0.75 to 70 atm, unburned gas temperatures from 298 to $550 \mathrm{~K}$, fuel-air equivalence ratio from 0.8 to 1.2 . Burning velocity decreases as diluents concentration increases due to the lower flame temperature.

A comprehensive research on $S_{u}{ }^{0}$, flammability limits and other fundamental combustion parameters of landfill gas (LFG) has been realized by Qin et al. (2001). A stagnation flow burner was used for the experimental work whereas two codes considering or not the heat reabsorption have been integrated with the Chemkin II using the GRI 2.11 mechanism for the description of the kinetics in the numerical study. The experiments have been conducted at atmospheric pressure and unburned gas temperature of $300 \mathrm{~K}$ along the stagnation streamline of the stagnation flow while the simulations were computed by employing the code that does not consider reabsorption. Experimental and simulations results show a reasonable agreement in general. As $\mathrm{CO}_{2}$ fraction increases, the flames become weaker, and the ability to operate fuel-lean diminishes.

Cardona and Amell (2013) studied the effect of adding $\mathrm{C}_{3} \mathrm{H}_{8}$ and $\mathrm{H}_{2}$ to $\mathrm{CH}_{4}(66 \%) / \mathrm{CO}_{2}(34 \%)$ biogas combustion at normal air and at slight oxygen enrichment air to solve the problem of biogas's low 
flexibility as a fuel for use in commonly used burners due to its low burning velocity. The results, along with the High Wobbe Index suggests that natural gas can be replaced by the biogas/propane/hydrogen mixture $\left(33 \% \mathrm{CH}_{4}-17 \% \mathrm{CO}_{2}-40 \% \mathrm{C}_{3} \mathrm{H}_{8}-10 \% \mathrm{H}_{2}\right)$. The High Wobbe Index is an index proportional to the thermal power of the system that permits interchangeability of fuels without changes in the combustion system geometry, injectors or gas supply conditions.

A detailed bibliographic revision with the state of the art on laminar burning velocity of biogas can be found in Pizzuti and coworkers (2016).

The objective of the present work is to describe in details the experimental setup and the experimental procedure of a new cylindrical constant volume combustion chamber (CVCC). The experimentally determined laminar burning velocity of biogas mixtures with initial pressures between 1 and 5 bar are presented and compared with simulation results.

\section{EXPERIMENTAL PROCEDURE AND DATA PROCESSING}

\section{Experimental setup}

The constant pressure, centrally ignited, spherically outwardly propagating flame (OPF) technique has been chosen in this investigation due to its capacity in reproducing thermodynamic conditions encountered in internal combustion engines. Therefore, a cylindrical CVCC has been designed, manufactured and validated for the experimental determination of the fundamental properties of biogas mixtures.

Figure 1a) shows a SolidWorks ${ }^{@}$ 3D visualization of the CVCC whereas Fig. 1b) presents an overview of the CVCC mounted on the optical table and relative instrumentation. The body of the chamber is made of a 304 steel cylinder of approximately $10 \mathrm{~mm}$ thickness, internal diameter of $150 \mathrm{~mm}$ and $170 \mathrm{~mm}$ length. The CVCC volume is approximately 4 liters and it is equipped with three windows for optical access. The rectangular windows are not used in the present investigation as well as the smaller round optical access, on the chamber side. Two acrylic windows, $170 \mathrm{~mm}$ in diameter and 40 $\mathrm{mm}$ thickness, with a visible access of $150 \mathrm{~mm}$ in diameter, used for viewing the flame front propagation from the ignition in the central region up to the wall, using schlieren technique. The body of CCVC has five additional entries. A hole for inlet and outlet of gases, two symmetrical entries that allow the accommodation of extended spark plugs responsible for ignition, an entry to place a K-type thermocouple for measuring the chamber.

Five high purity gases, i.e. $\mathrm{CO}(99.99 \%), \mathrm{CO}_{2}$

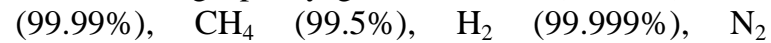
$(99.999 \%)$, stored in high-pressure cylinders, can be combined to form the desired fuel mixtures in a $20 \mathrm{~L}$ volume tank, using the partial pressure method and then injected in the CVCC. For simulated biogas mixtures only $\mathrm{CO}_{2}, \mathrm{~N}_{2}, \mathrm{CH}_{4}$ have been used.

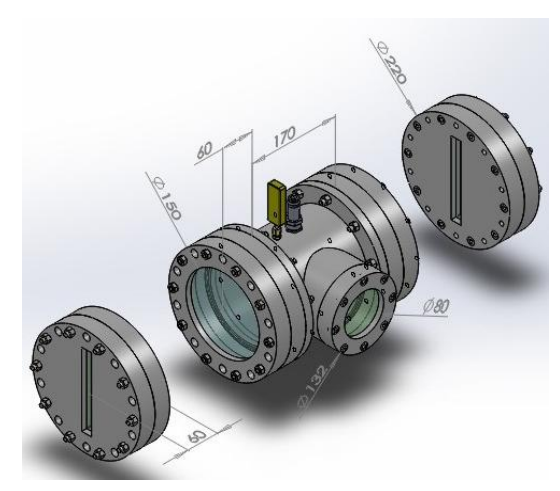

(a)

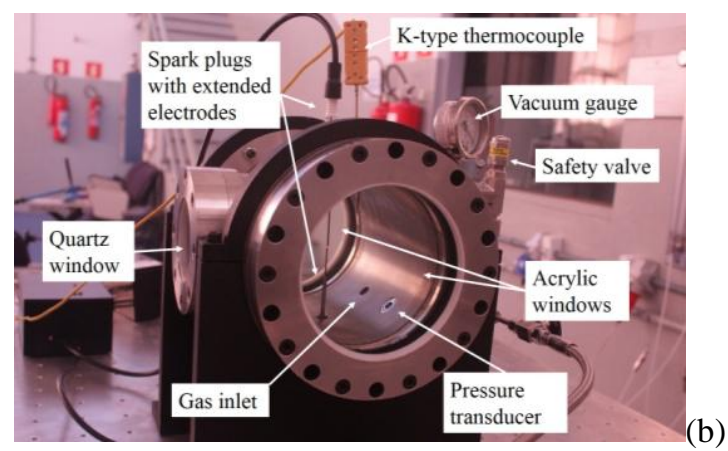

Figure 1. a) SolidWorks ${ }^{\circledR} 3 \mathrm{D}$ visualization of the CVCC. b) The CVCC mounted on the optical table.

The auxiliary cylinder allows preparing enough mixture to run all the repeated experiments with exactly the same mixture composition. Another advantage of this solution is that, preparing mixtures at higher pressures than the pressure of the experiment reduces the uncertainty associated to the absolute pressure transmitter. A digital absolute pressure transmitter, with uncertainty of $0.25 \%$ of full scale, ensures accurate control of the partial pressures and hence the achievement of the desired mixtures. A safety valve, calibrated to open at 39 bar of absolute pressure, and a vacuum gauge are installed along the gas filling system near the CCVC.

A vacuum pump is responsible for vacuum in the cylinder, the line and the CVCC thus creating the repeatable initial conditions necessary for a new experiment. The nominal vacuum is 10 mbar. A purge is present into the filling line to assist in the control of the pressure during cylinder and CCVC filling and for exhaust outlet.

A Perkin Elmer Clarus 580 gas chromatograph is used in order to verify the gas composition before injection in the CVCC. The mixture composition has been analyzed at least three times for each mixture.

A laboratory made ignition system comprises a $12 \mathrm{~V}$ source, an ignition module, a signal generator and two spark plugs. NGK AP5FS model automotive spark plugs have been equipped with extended 
electrodes made up of two parts: the first stainless steel part is welded to the electrode of the spark plug, the second thinner tungsten part is welded in the stainless steel part. In both cases, it is used oxyacetylene welding. One of the electrodes is provided with a thread that allows changing the length thereof. This allows controlling the distance between the electrodes, which is one of the parameters that influence the amount of energy available in the ignition. Most of the experiments have been realized using a gap of $1.5 \mathrm{~mm}$ for the initial pressure of three or less bar and a gap of 1.1 $\mathrm{mm}$ for the initial pressure of five bar.

A National Instrument Graphical User Interface (GUI) program written in LabVIEW is responsible for trigger management and data acquisition from experiments by using a National Instruments USB 6259 card. The LabVIEW program allows the trigger signal configuration (instant of start and signal duration) for the ignition module. Furthermore, it controls the data acquisition trigger of the high-speed camera, piezoelectric pressure transducer, and K-type thermocouple.

The flame propagation speed and the laminar flame burning velocity have been determined by using the schlieren techniques with a high-speed camera. For more details on this technique refer to (Settles, 2001).

The Z-type setup for schlieren visualization, presented in Fig. 2 has been chosen because it gives the best compromise between cost and benefits. A PCO Dimax S1 high-speed intensified CMOS camera, capable of taking up to 4467 frames per second (fps) at maximum resolution i.e. $1008 \times 1008$ pixels, and higher than $20000 \mathrm{fps}$ for lower resolution records the flame time evolution.

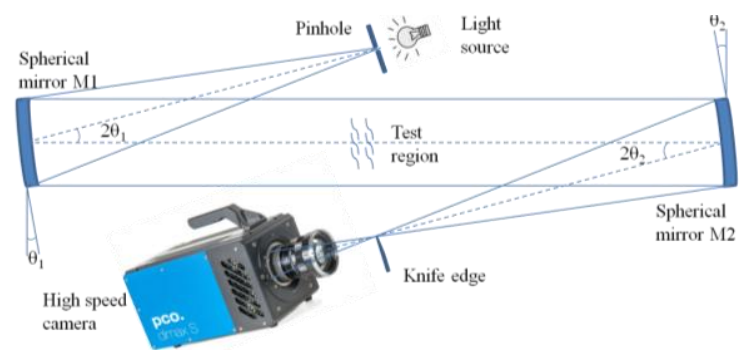

Figure 2. Z-type schlieren system setup. The two spherical mirrors have 6" $(\sim 15.24 \mathrm{~cm})$ diameter and 60" $(\sim 152.4 \mathrm{~cm})$ focal length.

The schlieren system allows recording the time evolution of the flame front. The large number of images obtained should be analyzed to determine the average radius of the flame front over time thus getting flame propagation velocity data used to determine the Markstein length, $L_{b}$ and $S_{u}{ }^{0}$. The image analysis is done through a program originally written in MATLAB ${ }^{\circledR}$ by Buffel and Bowens (2014) and released to be used freely. The program, originally used to analyze $\mathrm{CH}_{4}$ - air and ethanol - air flames, was adapted for biogas - air mixtures and the different configuration of the CVCC. The image analysis is done in two stages, the first responsible for determining the flame front radius time evolution and the second being responsible for determining $L_{b}$ and $S_{u}{ }^{0}$ by linear extrapolation.

The experimental setup and post-processing tools have been validated using $\mathrm{CH}_{4}$ /air mixtures at 1 bar and ambient temperature (Pizzuti et al., 2017).

\section{Laminar burning velocity}

The laminar burning velocity is determined using the optical technique. The assumption that natural convection does not influence the propagating spherical flame is considered. It implies that the unburned gas is isotropic and maintains its initial temperature, the burned gas does not diffuse and the pressure equalizes inside the reactor. The images of outwardly flame propagating, recorded using the schlieren technique, are used to determine the flame propagation speed, $S_{b}$, derived from the data of flame radius versus time:

$$
S_{b}=\frac{d r_{b}}{d t}
$$

where $r_{b}$ is the instantaneous flame radius and $t$ is the elapsed time from the spark ignition.

In real applications, it is impossible to generate adiabatic, planar, one-dimensional flames so that the flame front is always subjected to stretch effects. The flame response to stretch has been studied by many researchers (Clavin and Williams, 1982; Matalon and Matkowsky, 1982), by considering the Markstein length of the burned gases, $L_{b}$, which expresses the dependence of flame velocity on stretch (Giannakopoulos et al., 2015):

$$
S_{b}^{0}-S_{b}=L_{b} \kappa
$$

$S_{b}{ }^{0}$ is the unstretched flame propagation speed of the burned mixture and $S_{b}$ is given by Eq. (1). The stretch rate $\kappa$ is defined in each point of the flame surface, when $A$ is the flame front surface, as (Williams, 1985):

$$
\kappa=\frac{1}{A} \frac{d A}{d t}
$$

For a spherical flame, the stretch rate is given by:

$$
\kappa=\frac{1}{r_{b}} \frac{d r_{b}}{d t}=\frac{S_{b}}{r_{b}}
$$

Spherical flames are positively stretched flames 
due to their surface increase with time. In this method $S_{b}{ }^{0}$ is determined by linear extrapolation from the $S_{b}-$ $\kappa$ graph, as the intercepting value of $S_{b}$ when $\kappa=0$. The Markstein length, $L_{b}$, is determined from Eq. (2). The unstretched laminar burning velocity, $S_{u}{ }^{0}$, is determined by applying the continuity law to an ideally planar unstretched flame. $\rho_{b}$ and $\rho_{u}$ are the burned and unburned gas densities, respectively.

$$
S_{u}^{0}=S_{b}^{0} \frac{\rho_{b}}{\rho_{u}}
$$

\section{EXPERIMENTAL PROCEDURE}

This section presents the experimental procedure followed to increase repeatability and reduce uncertainties. The description follows the time sequence of operation starting with mixture preparation, mixture analysis with gas chromatography, standard gas test, CVCC filling with the mixture, ignition and data saving.

The mixture preparation in the auxiliary cylinder uses the partial pressure (PP) method. The auxiliary cylinder and filling line are purged down to atmospheric pressure. Then vacuum is made for 8 minutes. The auxiliary cylinder is filled with $\mathrm{N}_{2}$ up to 1 bar of absolute pressure. Then vacuum is made for another 8 minutes. This step guarantees that almost only $\mathrm{N}_{2}$ is left in the auxiliary cylinder. Fill the cylinder with $\mathrm{N}_{2}$ up to the calculated partial pressure for the mixture under analysis and wait until the pressure value does not change during $30 \mathrm{sec}$. Then close the auxiliary cylinder valve and vacuum the filling line for one minute. Repeat the filling procedure with the other gases of the mixture according to the partial pressure of each gas.

The mixture composition is verified by gas chromatography (GC). The GC of a standard mixture, meanly $\mathrm{CO}_{2}-\mathrm{N}_{2}=4.5-95.5 \%$, is made to verify the chromatograph setting before biogas mixture GC. For each mixture GC is repeated at least three times to verify the repeatability.

A test using a stoichiometric mixture of $\mathrm{CH}_{4}$ air at absolute pressure of 2 bar is carried out before each sequence of experiments with a biogas mixture to verify all the instrumentation and the schlieren system alignment.

The CVCC filling procedure comprises a vacuum time of the CVCC for 4 minutes, followed by a filling of the CVCC with the biogas mixture at 500 mbar. Vacuum is made in the CVCC for 4 more minutes and then filled with the biogas mixture at the desired initial pressure. This procedure is made in order to guarantees that almost only biogas mixture is present in the CVCC. A period of 5 minutes is considered enough for mixture rest and then it is ignited.

After burning the CVCC is purged to the atmosphere. Compressed air at 7 bar of absolute pressure is injected in the chamber for burning gases dilution and then purged to the atmosphere. This last step is repeated three times and then a new sequence can be started after data have been saved.

For each mixture at least five experiments are run. For each run a .txt file with pressure and temperature data is saved. The .jpg images for $S_{u}{ }^{0}$ determination are saved in the Exported Images subfolder while a raw pcoraw file is saved in the Raw File subfolder.

\section{Flame radius range for schlieren images analysis}

The flame propagation speed is not constant during flame propagation inside the CVCC. Immediately after the spark ignition, the flame propagation speed is influenced by the spark ignition energy and when it grows beyond a certain radius, it is influenced by the presence of chamber wall and instabilities on the flame front. Moreover, the hypothesis of constant pressure, necessary to apply the equation $S_{u}{ }^{0}=1 / \sigma S_{b}{ }^{0}$, where $\sigma=\rho_{u} / \rho_{b}$, is valid only in the first milliseconds after the ignition. Therefore, some consideration should be done in order to determine the correct range of flame radius and pressure values within which the $S_{u}{ }^{0}$ of an outwardly propagating flame should be determined.

According to Burke and coworkers (2007), the effect of chamber wall can be negligible up to a radius of $30 \%$ of the inner chamber radius. It means approximately $22.5 \mathrm{~mm}$ in the present installation. Singh et al. (2012) used $30 \mathrm{~mm}$ as their maximum flame radius measurement, which corresponds to $16.67 \%$ of the maximum chamber radius. Song et al. (2011) and Wang et al. (2012), considered $30 \mathrm{~mm}$ and $25 \mathrm{~mm}$ as their maximum flame radius measurement which corresponds to $27 \%$ and $28 \%$ of the maximum chamber radius thus respecting the criterion introduced by Burke. Burke et al. (2009), has found that, when the flame radius is $40 \%$ of the chamber radius, the pressure increase leads to an error in the flame propagation speed calculation by less than $1 \%$.

The maximum radius of flame used for flame propagation speed calculation should be determined by taking into account three factors: the chamber wall influence, the pressure raise and the appearance of instabilities.

With regarding to the pressure influence, the sensitivity of $S_{u}{ }^{0}$ with the pressure increase has been analyzed. The pressure criterion is based on the percentage pressure increase defined as follows:

$$
\Delta p=\frac{p_{i}-p_{0}}{p_{\max }} 100
$$

where $n=2000, p_{i}=p_{(t(i))}$ is the time pressure evolution and $p_{0}=p_{(t(0))}$, i.e., the pressure at the spark time. The maximum flame radius considered for $S_{u}{ }^{0}$ 
determination is the radius at the time the pressure criteria is reached, while the minimum radius is 8 $\mathrm{mm}$. Figure 3 shows the linear extrapolation for six pressure criteria while Tab. 1 presents the $S_{u}{ }^{0}, L_{b}$ and $\%$ sensitivity of the $S_{u}{ }^{0}$ on a $\Delta p$ variation of $0.1 \%$ as presented in Eq. (8), for stoichiometric $\mathrm{CH}_{4}$-air mixture.

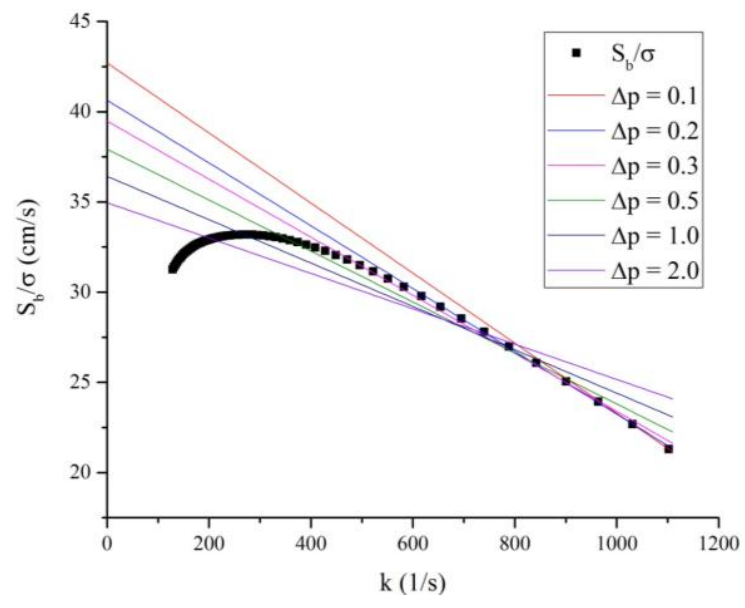

Figure 3. Linear extrapolation of $S_{u}{ }^{0}$ for six pressure criteria of stoichiometric $\mathrm{CH}_{4}$-air at $p=1$ bar.

Table 1. Laminar burning velocity and Markstein length for six pressure criteria of stoichiometric $\mathrm{CH}_{4}$ air at ambient temperature and pressure of 1 bar.

\begin{tabular}{|c|c|c|c|}
\hline Pressure criteria & $S_{u}{ }^{0}(\mathrm{~cm} / \mathrm{s})$ & $L_{b}(\mathrm{~mm})$ & Sensitivity $(\%)$ \\
\hline$\Delta \mathrm{p}<=0.1 \%$ & 42.706 & 1.451 & \\
\hline$\Delta \mathrm{p}<=0.2 \%$ & 40.641 & 1.301 & 4.84 \\
\hline$\Delta \mathrm{p}<=0.3 \%$ & 39.480 & 1.203 & 2.86 \\
\hline$\Delta \mathrm{p}<=0.5 \%$ & 37.931 & 1.056 & 1.96 \\
\hline$\Delta \mathrm{p}<=1.0 \%$ & 36.419 & 0.898 & 0.80 \\
\hline$\Delta \mathrm{p}<=2.0 \%$ & 34.960 & 0.732 & 0.40 \\
\hline
\end{tabular}
$S_{u}{ }^{0}$ :

The following equation is used for determining

$$
\frac{S_{b}}{\sigma}=S_{u}^{0}-\frac{L_{b} \kappa}{\sigma}
$$

The sensitivity of the $S_{u}{ }^{0}$ measurement on the pressure criteria has been determined as function of pressure variation of $\Delta p=0.1 \%$ using:

$$
\text { Sensitivity }=\frac{\left(S_{u}^{0}\right)_{1}-\left(S_{u}^{0}\right)_{2}}{\left(S_{u}^{0}\right)_{1}} \frac{0.1}{\Delta p_{2}-\Delta p_{1}} 100
$$

Noise affecting the pressure curve has been removed by applying a filter based on the following slope criteria: if $d p / d t>0.5$ then the $p_{(i+1)}=p_{(i)}$. In addition, a filter, which calculates the centered moving average of each point, has been applied to the pressure values.

Figure 4 relates the percentage pressure increase to the corresponding flame radius for three equivalence ratios of $\mathrm{CH}_{4}$-air mixtures. The pressure criteria of $\Delta p=0.5 \%$, for example, is reached when the flame radius is approximately 26,21 and $23 \mathrm{~mm}$, for $\phi=0.8,1.0$ and 1.2 , respectively. In stoichiometric mixtures of $\mathrm{CH}_{4}$-air, the pressure increase is faster than in other equivalence ratios. The $S_{u}{ }^{0}$ has shown to have a small sensitivity on the pressure increase criteria larger than $0.5 \%$. However, the hypothesis of constant pressure on which the model is based, suggest that a maximum pressure criteria of $0.5 \%$ should be used, thus limiting the flame radius used for $S_{u}{ }^{0}$ determination.

The third factor to consider when determining the maximum radius is the appearance of instabilities, which determines an increase in flame propagation speed. Therefore, only the range of flame radius not affected by instabilities should be taken into account to determine the correct $S_{u}{ }^{0}$. This range can be determined by visual inspection of the schlieren images of the outwardly propagating flame.

According to the literature review and the discussion here done, the range of radius used for $S_{u}{ }^{0}$ determination in the present research is the following: minimum radius $8 \mathrm{~mm}$, maximum radius determined by the stringiest criteria among $\Delta p=0.5 \%$ criteria, 18 $\mathrm{mm}$ or cellular instabilities onset.

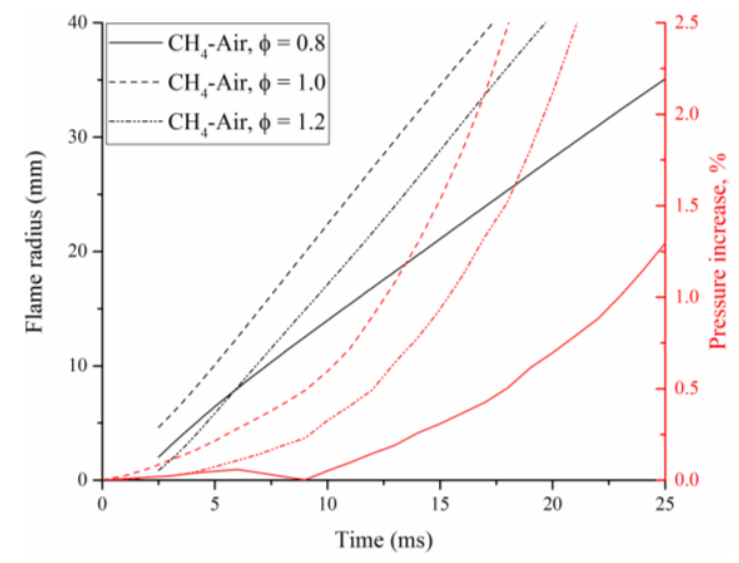

Figure 4. Pressure increase and corresponding flame radius. For $\phi=0.8$ the pressure increase is affected by some noise at small values, even after the filtering processing.

\section{RESULTS AND DISCUSSION}

The experimental $S_{u}{ }^{0}$ results have been compared with simulation data obtained from the Flame-speed Calculator CHEMKIN-PRO - Reaction Design 2008 software module using the complete GRI-Mech 3 and the San Diego reaction mechanisms in conjunction with their thermodynamic data and transport properties.

According to literature, the unstretched, adiabatic, freely-propagating planar flame can be simulated using CHEMKIN-PREMIX code to get $S_{u}{ }^{0}$ (Chen, 2015). The Flame-speed Calculator model simulates a 1-D freely propagating flame, in which the point of reference is a fixed position on the flame. The laminar flame speed by definition is the relative speed between the unburned gas mixture and the 
flame front. In this coordinate system, the flame speed is defined as the inlet velocity (velocity of unburned gas moving towards the flame) that allows the flame to stay in a fixed location, which is an eigenvalue of the solution method. This configuration is used to determine the characteristic flame speed of the gas mixture at specified pressure and inlet temperature. In this case, there are no heat losses and thus the temperatures should be computed from the energy equation. Flame speed depends, in part, on the transport of heat, and predicting the temperature distribution is an integral part of the flame speed calculation.

To set up the flame-speed calculation either the initial temperature, initial pressure and mixtures composition are specified as entrance parameters of the Flame-speed Calculator model. The grid parameters "maximum number of grid points allowed" and "ending axial point" have been varied in the range between 200 and 800 and $0.5 \mathrm{~cm}$ and 30 $\mathrm{cm}$, respectively. The values 400 and $20 \mathrm{~cm}$ have been adopted for giving grid independent results. Moreover, the inlet stream property of "inlet velocity" was set as default value, i.e. $40 \mathrm{~cm} / \mathrm{s}$. The default air composition is left as oxidizer. The default products of the complete combustion are set, i.e. $\mathrm{CO}_{2}$, $\mathrm{H}_{2} \mathrm{O}$, and $\mathrm{N}_{2}$.

Table 3 presents a comparison between the experimental and the simulated $S_{u}{ }^{0}$ for the studied biogas mixtures presented in Tab. 2. The simulated $S_{u}{ }^{0}$ are in fairly agreement between them however, the San Diego mechanism always provides lower values than the GRI-Mech 3.0. Most of the simulated $S_{u}{ }^{0}$ presents higher values than the experimentally determined $S_{u}^{0}$, except for mixture $\mathrm{N}^{\circ} 2$. The difference is higher for mixtures with smaller $S_{u}{ }^{0}$, while for $S_{u}{ }^{0}$ higher than $10 \mathrm{~cm} / \mathrm{s}$ the difference is usually lower than $12 \%$ for the San Diego mechanism and lower than $20 \%$ for the GRI-Mech.

For what concern repeatability 5 run for each mixture have been realized and Tab. 3 shows the standard deviation and percentage standard deviation of $S_{u}{ }^{0}$ of all biogas/air mixtures. The maximum percentage standard deviation of $S_{u}{ }^{0}$ is $8.11 \%$ while for most of the mixtures this value is lower than $3.55 \%$.

Table 2. Biogas mixtures $\left(\mathrm{CH}_{4} / \mathrm{CO}_{2} / \mathrm{N}_{2}\right) . \mathrm{N}^{\circ} \#$ means the number of the mixture.

\begin{tabular}{|c|c|c|c|c|}
\hline $\mathrm{N}^{\circ} \#$ & $\mathrm{CH}_{4} \%$ & $\mathrm{CO}_{2} / \mathrm{N}_{2}$ & $\mathrm{P}($ bar $)$ & $\phi$ \\
\hline 1 & 45 & 0.33 & 1 & 0.7 \\
\hline 2 & 45 & 1.5 & 5 & 1.1 \\
\hline 3 & 45 & 5 & 3 & 0.9 \\
\hline 4 & 55 & 0.33 & 3 & 1.1 \\
\hline 5 & 55 & 1.5 & 1 & 0.9 \\
\hline 6 & 55 & 5 & 5 & 0.7 \\
\hline 7 & 65 & 0.33 & 5 & 0.9 \\
\hline 8 & 65 & 1.5 & 3 & 0.7 \\
\hline 9 & 65 & 5 & 1 & 1.1 \\
\hline 10 & 55 & 1.5 & 3 & 1.1 \\
\hline 11 & 55 & 0.33 & 5 & 0.9 \\
\hline 12 & 65 & 5 & 3 & 1.1 \\
\hline
\end{tabular}

Table 3. Comparison of simulation and experimental results for $S_{u}^{0}$. The last two columns present the standard deviation and percentage standard deviation of $S_{u}{ }^{0}$ of all biogas/air mixtures. $\mathrm{N}^{\circ} \#$ is the number of the mixture.

\begin{tabular}{|c|c|c|c|c|c|}
\hline & \multicolumn{3}{|c|}{$S_{u}{ }^{0}(\mathrm{~cm} / \mathrm{s})$} & \multirow{2}{*}{$\sigma_{S_{u}^{0}}$} & $\sigma_{S_{u}^{0}} \%$ \\
\hline $\mathrm{N}^{\circ} \#$ & $\begin{array}{c}\text { GRI-Mech } \\
3.0\end{array}$ & $\begin{array}{c}\text { San } \\
\text { Diego }\end{array}$ & Experiments & & \\
\hline 1 & 12.5 & 12.0 & 9.6 & 0.60 & 6.23 \\
\hline 2 & 7.3 & 6.6 & 6.8 & 0.11 & 1.58 \\
\hline 3 & 10.1 & 9.9 & 8.7 & 0.27 & 3.12 \\
\hline 4 & 15.5 & 14.4 & 14.4 & 0.83 & 5.80 \\
\hline 5 & 22.6 & 21.5 & 21.2 & 1.70 & 8.02 \\
\hline 6 & 5.1 & 5.1 & 3.8 & 0.14 & 3.54 \\
\hline 7 & 12.5 & 12.3 & 10.7 & 0.08 & 0.75 \\
\hline 8 & 8.5 & 8.4 & 7.1 & 0.22 & 3.04 \\
\hline 9 & 27.0 & 24.6 & 21.6 & 1.75 & 8.11 \\
\hline 10 & 13.5 & 12.0 & 14.3 & 0.32 & 2.24 \\
\hline 11 & 11.3 & 11.1 & 10.5 & 0.22 & 2.09 \\
\hline 12 & 15.7 & 14.1 & 14.0 & 0.16 & 1.15 \\
\hline
\end{tabular}

Figure 5 shows the deviation of experimentally measured $S_{u}{ }^{0}$ from that predicted by simulation, $S_{u}^{0}{ }_{\text {(PREMIX) }}$, based on GRI-Mech. 3.0 and San Diego mechanisms provided in Tab. 3. Set of points for initial pressures of 1, 3, and 5 bar have been drawn. San Diego mechanism provides results fairly closer to experimental. However for both mechanisms the deviation is smaller close to stoichiometry while for $\phi$ $=0.7$ the deviation is larger than $15 \%$ for all pressures. It should be noted that, except for mixtures $\mathrm{N}^{\circ} 5$ and 9 whose $S_{u}{ }^{0}$ are higher than $15 \mathrm{~cm} / \mathrm{s}$ all other mixtures have $5 \leq S_{u}{ }^{0} \leq 15 \mathrm{~cm} / \mathrm{s}$. For the latter mixtures, buoyancy may affect the $S_{u}{ }^{0}$ determination, and its influence increases when $S_{u}^{0}$ decreases.

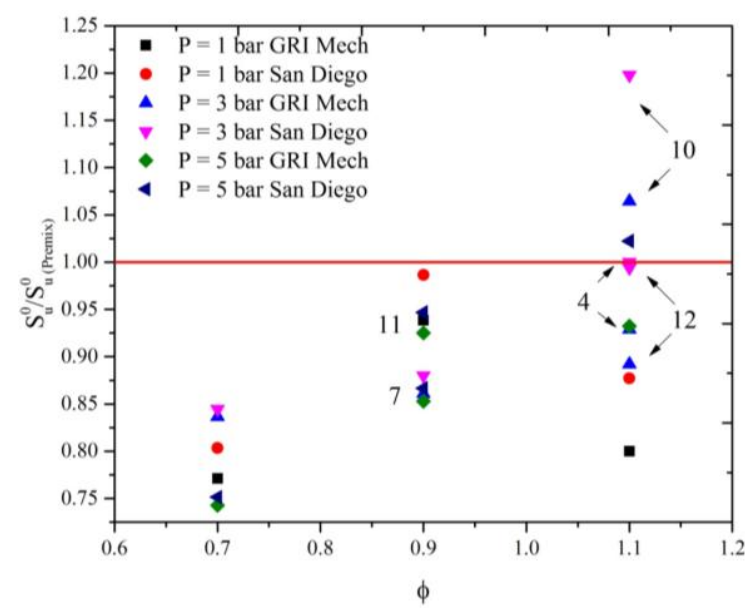

Figure 5. Deviation of $S_{u}{ }^{0}$ from that predicted by simulation using PREMIX for both GRI-Mech 3.0 and San Diego mechanisms. The numbers close to the symbols indicate the $\mathrm{N}^{\circ}$ of mixture in case of ambiguity.

\section{CONCLUSIONS}

In this paper, we have presented a new experimental device designed for laminar burning velocity determination. A fully detailed description of the experimental setup as well as the description of 
the experimental procedure followed for minimizing the sources of uncertainties has been presented. A detailed description of the determination of the range of flame radius used for laminar burning velocity has been discussed.

The laminar burning velocity of twelve biogas mixtures has been studied. Initial pressure varying between 1 and 5 bar, equivalence ratios between 0.7 and 1.1 and percentage dilution between 35 and $55 \%$ have been considered. Five experiments have been run for each mixture providing a maximum percentage standard deviation of $8.11 \%$. However, for most of the mixtures this value is lower than $3.55 \%$.

A comparison with simulation using PREMIX for both GRI-Mech 3.0 and San Diego mechanisms has provided closer agreement for mixtures with equivalence ratio closer to stoichiometry whereas for $\phi=0.7$ the deviation is larger than $15 \%$ for all pressures. Mixtures with lower equivalence ratio, higher dilution percentage and higher initial pressure present the lower values of laminar burning velocity. For those mixtures where $S_{u}{ }^{0}<15 \mathrm{~cm} / \mathrm{s}$, buoyancy may affect the laminar burning velocity determination, and its influence increases when $S_{u}{ }^{0}$ decreases.

\section{ACKNOWLEDGEMENTS}

The authors are grateful to the Brazilian federal agency CAPES for the financial support of a four years scholarship and the FAPESP (Fundação de Amparo à Pesquisa do Estado de São Paulo) agency for financially supporting the experimental project through the Process 2010/51315-3.

\section{REFERENCES}

Andrews, G. E., and Bradley, D., 1972, Determination of Burning Velocities: a Critical Review, Combustion and Flame, Vol. 18, pp. 133153.

Buffel, L., and Bauwens, J., 2014, Laminar Burning Velocity Measurements Using the GUCCI Setup, Master Thesis, Universiteit Gent, Gent, Belgium.

Burke, M. P., Chen, Z., Ju, Y., and Dryer, F. L., 2009, Effect of Cylindrical Confinement on the Determination of Laminar Flame Speeds Using Outwardly Propagating Flames, Combustion and Flame, Vol. 156, pp. 771-779.

Burke, M. P., Qin, X., Ju, Y., and Dryer, F. L., 2007, Measurements of Hydrogen Syngas Flame Speeds at Elevated Pressures, in: US Combustion Meeting, 5th - Combustion Institute, University of California, San Diego, USA.

Cardona, C. A., and Amell, A. A, 2013, Laminar Burning Velocity and Interchangeability Analysis of Biogas $/ \mathrm{C}_{3} \mathrm{H}_{8} / \mathrm{H}_{2}$ with Normal and Oxygen-Enriched Air, International Journal of
Hydrogen Energy, Vol. 38, pp. 7994-8001.

Chen, Z., 2015, On the Accuracy of Laminar Burning Velocity Measured from Propagating Spherical Flames: methane/air at Normal Temperature and Pressure, Combustion and Flame, Vol. 162, pp. 2242-2253.

Chen, Z., Burke, M. P., and Ju, Y., 2009, Effects of Lewis Number and Ignition Energy on the Determination of Laminar Flame Speed Using Propagating Spherical Flames, Proceedings of the Combustion Institute, Vol. 32, No. 1, pp. 1253-1260.

Clavin, P., and Williams, F. A., 1982, Effects of Molecular Diffusion and of Thermal Expansion on the Structure and Dynamics of Premixed Flames in Turbulent Flows of Large Scale and Low Intensity, Journal of Fluid Mechanics, Vol. 116, pp. 251-282.

Egolfopoulos, F. N., Hansen, N., Ju, Y., KohseHöinghaus, K., Law, C. K., and Qi, F., 2014, Advances and Challenges in Laminar Flame Experiments and Implications for Combustion Chemistry, Progress in Energy and Combustion Science, Vol. 43, pp. 36-67.

Elia, M., Ulinski, M., and Metghalchi, M., 2001, Laminar Burning Velocity of Methane-Air-Diluent Mixtures, Journal of Engineering for Gas Turbines and Power, Vol. 123, No. 1, pp.190-196.

Giannkopoulos, G. K., Gatzouliz, A., Frouzakis, C. E., Matalon, M., and Tomboulides, A. G., 2015, Consistent Definitions of "Flame Displacement Speed" and "Markstein Length" for Premixed Flame Propagation, Combustion and Flame, Vol. 162, No. 4, pp. 1249-1264.

Huzayyin, A. S., Moneib, H. A., Shehatta, M. S., and Attia, A. M. A., 2008, Laminar Burning Velocity and Explosion Index of LPG-Air and Propane-Air Mixtures, Fuel, Vol. 87, No. 1, pp. 39-57.

Matalon, M., and Matkowsky, B. J., 1982, Flames as Gasdynamic Discontinuities, Journal of Fluid Mechanics, Vol. 124, pp. 239-259.

Mihic, S., 2004, Biogas Fuel for Internal Combustion Engines, Annals of the Faculty of Engineering Hunedoara, Vol. 2, No. 3, pp. 179-190.

Noyola, A., Morgan-Sagastume, J. M., and Lopez-Hernandez, J. E., 2006, Treatment of Biogas Produced in Anaerobic Reactors for Domestic Wastewater: odor Control and Energy/Resource Recovery, Reviews in Environmental Science and Bio/Technology, Vol. 5, No. 1, pp. 93-114.

Pizzuti, L., Martins, C. A., and Lacava, P. T., 2016, Laminar Burning Velocity and Flammability Limits in Biogas: a Literature Review, Renewable and Sustainable Energy Reviews, Vol. 62, pp. 856865.

Pizzuti, L., Martins, C. A., Santos, L. R., and Guerra, D. R. S., 2017, Laminar Burning Velocity of Methane/Air Mixtures and Flame Propagation Speed Close to the Chamber Wall, Energy Procedia, Vol. 120, pp. 126-133.

Qin, W., Egolfopoulos, F. N., and Tsotsis, T. T., 2001, Fundamental and Environmental Aspects of 
Landfill Gas Utilization for Power Generation, Chemical Engineering Journal, Vol. 82, No. 1-3, pp. 157-172.

Rallis, C. J., and Garforth, A. M., 1980, Determination of Laminar Burning Velocity, Progress in Energy and Combustion Science, Vol. 6, pp. 303-329.

Rasi, S., 2009, Biogas Composition and Upgrading to Biomethane Saija Rasi Biogas Composition and Upgrading to Biomethane, Master Thesis, University of Jyvaskyla, Jyvaskyla.

Settles, G. S., 2001, Schlieren and Shadowgraph Techniques: visualizing Phenomena in Transparent Media, Springer-Verlag GmbH.

Singh, D., Nishiie, T., Tanvir, S., and Qiao, L., 2012, An Experimental and Kinetic Study of Syngas/Air Combustion at Elevated Temperatures and the Effect of Water Addition, Fuel, Vol. 94, pp. 448-456.

Song, W. S., Vu, T. M., Park, J., Kwon, O. B., You, H. S., and Yun J. H., 2011, Measurements of Laminar Burning Velocities and Flame Stability Analysis of Biomass Derived Gas: air Premixed Flames, in: Seventhy Mediterranean Combustion Symposium - Diagnostics and Radiative Transfer, CDRT-6, Chia Laguna, Cagliari, Sandinia, Italy.

Wang, J., Huang, Z., Kobayashi, H., and Ogami, Y., 2012, Laminar Burning Velocities and Flame Characteristics of $\mathrm{CO}-\mathrm{H}_{2}-\mathrm{CO}_{2}-\mathrm{O}_{2}$ Mixtures, International Journal of Hydrogen Energy, Vol. 37, No. 24, pp. 19158-19167.

Williams, F. A., 1985, Combustion Theory: the Fundamental Theory of Chemically Reacting Flow System, The Benjamin/Cummings Publishing Company, Inc. 